$61 \mathrm{ft}$. wide and $64 \mathrm{ft}$. deep ; it is above the contourlevels frequented by shepherds and herds, and so has remained undisturbed by modern intruders. On the other hand, the plentiful remains of wild mountain goats found in the deposits evole no surprise. There were four black archæological levels separated by clay-like sterile ones, but the industries from bottom to top showed no great culture-change.

The tools are well made of local flinty limestone, quartzite, prase, etc., and include scrapers, disks, flakes and a sort of rough Audi knife (judging from the illustrations) as well as "utilised" bones. There were no real bone tools. It seemed not unreasonable to assign the whole industry to a late Mousterian culture, and this conclusion was confirmed when the skull of a 7-8-year-old child showing unmistakable Neanderthal characteristics was unearthed from definitely within the uppermost archæological level. A point of especial interest was that the skull appeared to have been partly surrounded by a ring of goats' horns arranged in pairs. Indeed, it seems evident that a ceremonial or ritual burial comparable to those of La Ferrassie in France had taken place as far away from western Europe as Tashkent. Geographically nearer, comparisons of implements can be made between the new Teshik-Tash finds and those of such Russian flake-tool sites as Chokurcha, Akhtyr, etc.; but the appearance of a Neanderthal ritual burial puts the former in a different category, enables a more precise dating to be made, and is intrinsically exciting, opening up as it does new ideas as to the possible distribution of the Neanderthal race.

\section{Radiography of the Chest in Recruits}

Aт a meeting of the Section of Medicine of the Royal Society of Medicine on May 27, Dr. Philip Ellman read a paper on "Mass Radiography of the Chest in the Early Detection of Intrathoracic Disease, with Special Reference to Pulmonary Tuberculosis in Recruits", in which he maintained that this method offers an invaluable contribution to preventive medicine. He recorded some results which he had obtained by (1) full-sized radiograms, (2) fluoroscopy and (3) miniature screen photography, the last being the most practical means of carrying out mass X-ray examination of the chest. As the result of his experience of this method with control experiments with full-sized radiograms, he suggested that for correct interpretation miniature screen photography demands a technically satisfactory film, which involves the closer co-operation of technician, radiologist and chest physician. The method offers an invaluable contribution to the detection of pre-clinical asymptomatic pulmonary lesions in a presumably healthy population. It can therefore add much to the prevention and control of pulmonary tuberculosis-in war by the examination of recruits, and in peace by the examination of selected groups of the population, for example, where pulmonary tuberculosis is known to be frequent and in certain trades where the pneumokonioses are known to be common. In dealing with the application of the method to cardiology in the detection of cardiovascular lesions, Dr. Ellman urged that serial examinations should be made, and that its general adoption in routine health examinations will be of great value.

\section{The Farmers Club Library}

The Farmers' Club (2 Whitehall Court, London, S.W.1) has recently added considerably to its library. To extend the use of it, a loan service is being instituted by which members (now numbering 1,320) may borrow books, free of charge. A classified catalogue of the library has been printed, and supplemental lists will be added from time to time. The range of subjects covered is comprehensive, and the dates of publication extend from the eighteenth century up to the present day. Suggestions for additions to the library will be welcomed from members, and inquiries for books not listed in the catalogue may be made as they may be obtainable from other sources. The addition of an author index in any further issues of the catalogue would add considerably to its valuo

\section{River Flow Records}

IT is now two years (June 3,1939 ) since there was noticed in these columns an annual report (the third) on Inland Water Survey in Great Britain, issued by the Ministry of Health and the Scottish Office. Unfortunately, there seems to be little or no likelihood that further reports will be published at present. This abrupt cessation of the reports makes a serious hiatus in the useful work of the Survey, which was begun by the Government in 1935 at the instance of the British Association and the Institution of Civil Engineers, and it is greatly to be regretted from a hydrological point of view, since the data collected were, undoubtedly, of great value for a properly systematized estimation of the water resources of the country. To remedy the omission in some measure, Captain W. N. McClean, the director of River Flow Records (Parliament Mansions, Victoria Street, S.W.1), to whose initiative and enterprise the institution of the Survey is due, has just issued a small pamphlet of ten sheets, entitled "River Flow Records of the River Moriston at Invermoriston", giving recorded readings of that river in Inverness-shire during the years 1937-40, in continuation of those which have previously been recorded since 1929 . Both water-levels and river flow have been tabulated daily for each month of the period to September 1940 . The relationship between them has been established at Invermoriston for any water-level up to an ordinary high flood. Extreme low flow may drop to less than $30 \mathrm{cu}$. ft. per sec., and an extreme high flood may reach a flow of $16,000 \mathrm{cu}$. ft. per sec. The area drained is 151 square miles and the run-off for a year of average rainfall is estimated to be about 68 inches. Captain McClean's persistent and painstaking efforts in maintaining these scientific observations are deserving of the highest commendation. It is greatly to be desired that publication of the results of the national survey should be resumed as soon as possible. 